\title{
RESEARCH PAPER \\ ENHANCING PASSENGER SAFETY AND SECURITY IN GHANA: APPRAISING PUBLIC TRANSPORT OPERATORS' RECENT INTERVENTIONS
}

\author{
E. F. Sam ${ }^{1,2}$ and A. M. Abane $^{3}$

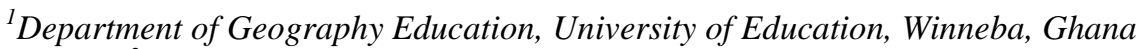 \\ ${ }^{2}$ Hasselt University, Transportation Research Institute (IMOB), \\ Agoralaan, 3590 Diepenbeek, Belgium \\ ${ }^{3}$ Department of Geography and Regional Planning, University of Cape Coast, Ghana \\ Corresponding author: efsam@uew.edu.gh
}

\begin{abstract}
There are increasing calls for regular monitoring and evaluation of safety and security strategies of public transport (PT) operators, especially in developing countries where PT safety and security concerns abound. In respect of this, this study examined the passenger safety and security interventions of PT operators in Ghana. Both the accident-incident theory and routine activities theory served as the theoretical framework within which the study was rooted. Guided by the convergent parallel mixed methods design, data were drawn from in-depth interviews with six major intercity PT operators as well as questionnaires administered to 273 intercity PT passengers. The field data were analysed using both thematic (qualitative data) and correlational (quantitative data) analyses in line with the study design. Varied perspectives on the state of PT passenger safety and security in the country were expressed, and operators' interventions in this regard were appraised. The study emphasised the need for periodic review of the regulatory framework establishing public transport undertaking by the Metropolitan, Municipal and District Assemblies (MMDAs) to reflect changing safety and security circumstances.
\end{abstract}

Keywords: Public transport operators, passenger safety, security, interventions, Ghana

\section{INTRODUCTION}

According to the National Road Safety Commission (NRSC, 2010), more than 200,000 road traffic accidents were recorded in Ghana over the last two decades, i.e.1991-2010. Of these accidents, $16.4 \%$ involved public transport (PT) vehicles (buses and minibuses). Over the period, the number of buses and minibuses in- volved in accidents increased consistently from 288 in 1991 to 4,705 in 2000 , reducing slightly to 4,192 in 2010 . As high occupancy modes, buses and minibuses accidents have produced consistently high casualties (from 2,706 in 1991 to 5,777 in 2010) in the country (NRSC, 2010).

In Ghana, bus and minibus passengers occupy 


\section{Sam and Abane}

an unenviable second position $(20.3 \%$ of total fatalities) when it comes to road users with the largest share of fatalities; second only to pedestrians with $43.3 \%$ (NRSC, 2010). This definitely undermines PT mode share and efforts to promote sustainable PT use. Consequently, safe PT systems are fundamental to improving safe mobility and social inclusion (World Health Organisation (WHO), 2013; Newton, 2014).

In promoting sustainable PT use, PT experience ought to be pleasant for all passengers. Fundamental to a pleasant trip, however, is passengers' personal safety and security. Unfortunately, public transportation in itself poses a higher safety and security risk as it conveys a larger number of commuters at a time (Joewono and Kubota, 2006). PT use thus increases the degree of potential exposure to both safety and security concerns (Stafford, 2003), and consequently passengers' perception of personal safety and security (Potoglou et al., 2010). However, it must be noted that unlike personal safety, personal security while engaged in transport activity is not a transport problem, but a social malaise (World Bank, n.d).

This notwithstanding, several researchers have underscored the importance of personal safety and security in determining mode share, operator choices and travel frequency (Sam et al., 2014; Forsblom, 2002; Benjamin et al., 1994; Ingalls et al., 1994). Sam et al. (2014) have observed that passengers' perception of safety and security ranked high in their PT operator choices. Personal safety and security concerns on PT results in passengers' poor rating of the service with implications for patronage (Reed et al., 2000).

To attract more patrons, PT should be of a "sufficiently high quality" (Mackett and Babalik, 2003). Iles (2005) suggested that "service quality embracing reliability, punctuality, safety, convenience, comfort and security, should be the first responsibility of a transport undertaking to its customers" (p. 379). Given that the way PT is organised and operated affect passengers' safety and security (Iles, 2005; Lynch and Atkins, 1988), there are increasing calls for regular monitoring and evaluation of the safety and security strategies employed by PT operators (Needle and Cobb, 1997; Iles, 2005). On the basis of this call, this paper examines recent (within the past three years) safety and security interventions of PT operators in Ghana. An appraisal of these interventions by both operators and passengers (PT users) was also reported in the study. In this study, passenger safety was defined as vulnerability to accident and/or injury involving a PT vehicle while passenger security was examined as vulnerability to intentional criminal and antisocial acts such as robbery, assault, and baggage theft while on a PT.

\section{THEORETICAL FRAMEWORK}

The accident-incident theory and the routine activities theory form the theoretical basis for explaining and predicting passenger (un) safety, accidents and (in) security, crime and antisocial acts on PT in Ghana. Peterson (1975) proposed the accident-incident theory as an extension of the human factors theory, to explain industrial accident causation and prevention. In addition to the elements of the human factors theory (overload, inappropriate response and inappropriate activities), Petersen introduced such new concepts as ergonomic traps, the decision to err, and systems failures, which lead to human error and subsequently accident occurrence. This study borrows the systems failure component of the theory in demonstrating the need for interventions in enhancing PT passenger safety and security. According to Petersen (1975) a system failure (in this case PT system failure, evident in rampant $\mathrm{PT}$ incidents including road accidents, crime and antisocial acts suffered by PT passengers) may result from failure on the part of management (in this case PT operators) to establish explicit safety and security policies and interventions. Also, insufficient safety and security orientation and training to employees (in this case bus drivers and ancillary staff) may also result in system failure. These lapses can 
result in PT safety (road accidents) and security concerns.

Thus as PT management ensure proper functioning of the PT system through implementing relevant safety and security interventions, the concomitant effect will be reduced PT incidents and invariably improved passenger safety and security. Some appropriate interventions may be driver skill and competence development and redevelopment, use of safer vehicles, adherence to strict maintenance and servicing schedules, active surveillance (police and other security patrols, CCTV), baggage identification system, and well-lit terminals. However, in order to fully understand how the public transport system bleeds security concerns, the routine activities theory propounded by Cohen and Felson (1979) was incorporated. As indicated by Newton (2014), the PT system provides a unique setting, in terms of places and times, for crime and antisocial acts. Connected to this is the notion that PT network can act as both attractors and generators of crime and antisocial acts (Smith and Cornish, 2006; Clarke and Eck, 2005), given that it attracts a larger number of both commuters and potential commuters over time and space.

The routine activities theory suggests that the incident of crime hinges on three elements: a suitable target or victim, a motivated offender and the absence of a capable guardian. Suitable targets on the PT system varies and may include passengers, baggage and even staff (Newton, 2014), while capable guardian (s) may include hired or employed police and other law enforcement officials on board PT buses and/ or at terminals, surveillance system (CCTV or a sign of it), well-lit terminals and properly instituted baggage identification system. According to the theory, when a motivated offender and a suitable target (passenger, baggage) meet in the absence of capable guardian (s) (law enforcement agents, surveillance system), there is the likelihood of crime or antisocial act.

In the nutshell, the likelihood of motivated of- fenders having contact with suitable targets increases with increased day to day activities (routine activities) in public spaces (Branic, 2015). Moreso, Newton (2014) demonstrated that "the dynamic nature of public transport system creates unique environments, through which specific modes of transport traverse, transporting potential targets and victims, on a system that passes through areas with different levels of crime risk, and therefore continuously receives different inputs and outputs over time. This creates a unique, potentially specialised, and a certainly concentrated arena within which crime and disorder may occur" (p.711). By implication reducing "criminal opportunity contexts" is useful in reducing the prevalence of crime (Branic, 2015; Cohen and Felson, 1979). However, as noted by Branic (2015), "it is important to note that routine activities theory offers suggestions about the probability of a criminal behaviour rather than making definite claims about when crime will occur" (para. 3).

Thus PT systems failure and incapable guardianship from transport operators and relevant stakeholders may dictate the state of PT passenger safety and security over time and space and will continue to be so unless these issues are tackled via appropriate interventions.

\section{METHODS}

\section{Research design}

The convergent parallel mixed methods research design was employed for data collection and analysis. Central to this design is the issue of gathering both qualitative and quantitative forms of data using the same or parallel variables, constructs or concepts, with the intent to gain both an in-depth perspective (the aim of the qualitative approach) and to generalise to a population (the aim of the quantitative approach). Both outcomes (qualitative and quantitative findings) are then related to inform interpretation (see Creswell, 2014, p.269).

\section{Sampling procedure}

Three major capital cities (Accra, Kumasi and Tamale), drawn from the three ecological zones 


\section{Sam and Abane}

- coastal, forest and savannah respectively- in Ghana, constituted the study sites. These were selected on merit as they are centres of commerce and trip-generating activities, hence play significant roles in the urban transport space, generating and distributing thousands of both intercity and intra-city trips daily. Within each city, two dominant intercity terminals from the host of available PT loading terminals were selected as data collection points.

Patrons of intercity, long distance bus and minibus services in the selected cities were targeted given the passenger safety and security concerns with this PT service in Ghana. About two -thirds of PT accidents in Ghana occur on intercity roads. Availability at selected terminals at the time of the survey and willingness to participate in the study formed the basis for participant selection. Hundred (100) questionnaires were assigned to each of the 3 study areas. Of the questionnaires administered, 273 (89 from Accra, 93 from Kumasi and 91 from Tamale) were usable. The remaining 27 had some missing responses on key variables, so they were excluded in the analysis.

On the other hand, six PT operators (Ghana Private Road Transport Union (GPRTU), Metro Mass Transit (MMT) Ltd, Intercity State Transport Coaches (ISTC) Ltd, VIP Transport, O.A. Travel and Tours, and VVIP Transport) were selected on the basis of their willingness to grant an interview. Coincidentally, these operators include some of the major players in the urban transport space by virtue of their market share of commuters and popularity.

\section{Data collection procedure}

Data for the study came from questionnaires administered to intercity, long distance bus passengers as well as in-depth interviews with officials from the six intercity PT operators. The questionnaires featured both open and closed-ended questions on the state of PT passenger safety and security in the country and knowledge of and assessment of PT safety and security interventions of operators in the coun- try. The interviews also explored operators' assessment of PT passenger safety and security situation in the country, operator-specific interventions implemented in this regard as well as their personal assessment of the impact of these interventions on the general PT passenger safety and security in the country.

Data gathering (both interview schedules and questionnaire administration) were done simultaneously between $17^{\text {th }}$ November 2014 and $21^{\text {st }}$ January 2015. To ensure validity, study findings were linked to previous findings and literature to ascertain how they relate to what is already known. Moreover, the survey questions were explained, and in some cases translated into the dominant dialect of the respondents, to ensure they adequately understood what is required of them. To this end, six research assistants (two for each study area) were trained and oriented on the survey questions and their objectives. Using the same instruments (questionnaire and interview guide) for all respondents helped ensure the reliability of the study findings.

\section{Data analysis and presentation}

Qualitative data from the interview schedules and the open-ended questions on the questionnaire were coded (both open and focused coding) to generate categories and themes and later analysed using the thematic analytic strategy. Verbatim transcription and presentation of the interview data were done. However, the quantitative data from the questionnaires were analysed using the descriptive (means and standard deviation) and correlational statistical techniques and presented using frequency tables. The "side-by-side comparison" approach typical of the convergent parallel mixed methods design (see Creswell, 2014) was used in presenting and discussing the qualitative and quantitative findings. Both PT users and operators' perspectives on the state of PT passenger safety and security in the country and operators' recent interventions are elucidated. 
Passenger safety and security interventions of PT operators... 105

\section{Participants}

Table 1 presents some demographic information of the passengers. The surveyed passengers included 178 males $(65.2 \%)$,between the ages of 15 and 62 years $(M=30.2, S D=9.8)$, who had attained tertiary education and travelled three to five times weekly using PT.

Analysing the age distribution further, $84.3 \%$ of the participants (passengers) could be described as belonging to the "economically active group", with implications for demand and patronage of urban transport services. Consequently, given the relatively low private vehicle use among the Ghanaian working class, PT use seem to be the most suitable alternative for work trips and other commuting purposes (see Abane, 1993b, 2011). Typical of the study participants (based on educational attainment and travel frequency), Poku-Boansi and Adarkwa (2013) argued that, "people with formal education are usually engaged in activities that may generate increased number of trips" (p.64); thus implying relatively high routine activities over time and space.
However, the six officials interviewed were males between the ages of 39 and 54 years and worked as Transport and/or Traffic Operations Managers in their respective organisations, with responsibilities for ensuring passenger safety and security and thus fulfilling the operators' vision of providing safe and secure passenger mobility. The youngest operator in the urban transport business at the time had operated for nearly four years.

\section{RESULTS AND DISCUSSION}

Perceived state of passenger safety and security in Ghana

To provide the basis for discussing and appraising the operators' safety and security interventions, the study first sought to understand the prevailing PT passenger safety and security situation in the country from the operators' and passengers' perspectives. Analysis of the data revealed mixed reactions. On their part, twothirds (4 out of 6) of the operators alluded to an improved PT passenger safety situation in the country. This notwithstanding, a critical operator revealed:

Table 1: Passengers' demographic information

\begin{tabular}{llcc}
\hline Variable & & Frequency & Percent \\
\hline Sex & Male & 178 & 65.2 \\
Age & Female & 95 & 34.8 \\
& $15-20$ years & 33 & 12.0 \\
& $21-26$ years & 95 & 34.8 \\
& $27-32$ years & 70 & 25.6 \\
& $33-38$ years & 30 & 11.0 \\
& 39-44 years & 13 & 4.8 \\
& 45-50 years & 15 & 5.5 \\
& $51-56$ years & 7 & 2.6 \\
Education (highest level attained) & 57-62 years & 10 & 3.7 \\
& No formal education & 17 & 6.2 \\
& Basic & 38 & 13.9 \\
& Secondary/ Vocational & 84 & 30.8 \\
Frequency of PT use & Tertiary & 134 & 49.1 \\
& Every single day in a week & 107 & 39.2 \\
\hline
\end{tabular}


We are making some improvements but it leaves much more to be desired. Nationally, our safety profile is that poor. Public transport operators (I am talking generic to include private operators and the various unions) do not take safety as the main feature of the service that we provide. For instance, you have a vehicle that clearly is showing defects from the station but they will ignore it and load passengers and mainstream somewhere it develops a problem and that problem could lead to a lot of things (Traffic Control Manager, Male respondent, 39 years).

In connection with the above, Table 2 presents passengers' perception and feeling of safety on PT vehicles in the country. Of the 273 passengers surveyed, $58.2 \%$ believe PT passengers in the country are not safe, and this is an indication of a system failure according to the accident-incident theory. This confirms Iles' (2005) assertion in his book "Public transport in developing countries", that PT passengers in developing countries are not safe as a result of the poor safety records of long distance buses in these countries. Corroborating Iles' assertion and the operator's view (as quoted above), a passenger bemoaned: "Passengers' safety is always in a mess; drivers only think about the money. What they do is drive fast to get the next passenger" (Male respondent, 32 years). This notwithstanding, some passengers $(41.8 \%)$ believe the situation has improved over time.

As the basis for passengers' assessment above, a fair proportion $(26.4 \%)$ of them claimed to have personally been involved in road accidents while aboard PT vehicles in the country. It is not surprising that nearly $68 \%$ (185) of them had ever felt unsafe on a PT, and this was attributed to the media reportage on PT road accidents in the country (39.5\%) as well as their previous involvement in road accidents while aboard a PT vehicle $(38.9 \%)$. Careless driving by some bus drivers in the country was also a safety concern for a section of the passengers. This, according to the accident-incident theory, may stem from a failure on the part of manage- ment (PT operators) to adequately orient and train their drivers on safety policies and procedures.

Reactions on passengers' security on PT vehicles in the country was also mixed. Operators, on the one hand, were unequivocal in their belief that the security of passengers on PT vehicles had seen significant improvement in the country, courtesy increased police highway visibility and some of their own internal interventions (capable guardianship). However, passengers think otherwise; the majority (64.1\%) still perceive they are not secure on PT.

Table 2 indicates that $46.2 \%$ (126) of the passengers had experienced some security challenges on PT in Ghana in the past. Of this number, $40.5 \%$ had suffered baggage theft, assault $(34.1 \%)$ and highway robbery attacks $(25.4 \%)$, and all these are indicative of both system failure and lack of capable guardianship. On the whole, the study revealed that passengers' previous safety and security challenges on PT vehicles as well as media reportage on PT safety and security concerns formed the basis for their perceived safety and security evaluations. Further analysis of the data revealed that respondents' assessment of the current PT passenger safety, unlike passenger security, in the country was influenced by their frequent PT use ( $r=.33$, $\mathrm{n}=157, \mathrm{p}=.000$ ). Given that perception and reality are not always the same, Benjamin et al. (1994) and Wallace et al. (1999) suggested that passenger safety and security evaluations be based on the frequency and severity of the incident.

Safety and security interventions of intercity transport operators in Ghana

Given that there is no incident-free (perfect) PT system and also that the system both attract and generate crime and antisocial acts, the need for appropriate interventions is paramount. Moreso, the findings presented above support the need for interventions to address the various concerns raised. 
Passenger safety and security interventions of PT operators... 107

Table 2: Passengers assessment of their safety and security on PT vehicles in Ghana

\begin{tabular}{|c|c|c|c|}
\hline Assessment & & Frequency & Percent \\
\hline \multirow{2}{*}{$\begin{array}{l}\text { Passengers assessment of their } \\
\text { safety on PT vehicles in Ghana }\end{array}$} & Passengers are not safe & 159 & 58.2 \\
\hline & Passenger safety has improved & 114 & 41.8 \\
\hline \multirow{2}{*}{$\begin{array}{l}\text { Personal accident encounter while } \\
\text { aboard PT vehicle }\end{array}$} & Yes & 72 & 26.4 \\
\hline & No & 201 & 73.6 \\
\hline \multirow{2}{*}{$\begin{array}{l}\text { Feelings of unsafety while on PT } \\
\text { vehicle }\end{array}$} & Yes & 185 & 67.8 \\
\hline & No & 88 & 32.2 \\
\hline \multirow[t]{5}{*}{$\begin{array}{l}\text { Cause of unsafe feelings on PT } \\
\text { vehicle }\end{array}$} & $\begin{array}{l}\text { Personal involvement in road accident } \\
\text { while on a PT vehicle }\end{array}$ & 72 & 38.9 \\
\hline & Road accident involving someone I & & \\
\hline & know & 25 & 13.5 \\
\hline & $\begin{array}{l}\text { Media reportage on increased PT road } \\
\text { accidents in the country }\end{array}$ & 73 & 39.5 \\
\hline & $\begin{array}{l}\text { Careless driving by bus drivers in the } \\
\text { country }\end{array}$ & 15 & 8.1 \\
\hline \multirow{2}{*}{$\begin{array}{l}\text { Passengers' assessment of their } \\
\text { security on PT vehicles in Ghana }\end{array}$} & Passengers are not secure & 175 & 64.1 \\
\hline & Passenger security has improved & 98 & 35.9 \\
\hline \multirow{2}{*}{$\begin{array}{l}\text { Personal security challenges while } \\
\text { on PT vehicle }\end{array}$} & Yes & 126 & 46.2 \\
\hline & No & 147 & 53.8 \\
\hline \multirow{3}{*}{$\begin{array}{l}\text { Form of insecurity suffered by } \\
\text { respondents }\end{array}$} & Assault & 43 & 34.1 \\
\hline & Highway robbery attack & 32 & 25.4 \\
\hline & Baggage theft & 51 & 40.5 \\
\hline \multirow{2}{*}{$\begin{array}{l}\text { Feeling of insecurity while on PT } \\
\text { vehicle }\end{array}$} & Yes & 161 & 59.0 \\
\hline & No & 112 & 41.0 \\
\hline \multirow{4}{*}{$\begin{array}{l}\text { Cause of feeling of insecurity on } \\
\text { PT vehicle }\end{array}$} & Personal security challenges on a PT & 58 & 36.0 \\
\hline & vehicle & 43 & 26.7 \\
\hline & $\begin{array}{l}\text { Security concerns experienced by some- } \\
\text { one I know }\end{array}$ & 53 & 33.0 \\
\hline & $\begin{array}{l}\text { Media reportage on highway robbery } \\
\text { attacks on PT passengers in the country } \\
\text { Failure of police escort to turn up for } \\
\text { scheduled journey }\end{array}$ & 7 & 4.3 \\
\hline
\end{tabular}

The interviews with the PT officials revealed a number of safety and security interventions adopted by their respective organisations. To ensure accident-free ride and passengers' safety, the following safety interventions were being implemented by the operators (a summary of operator-specific interventions) at the time of the survey: strict adherence to vehicle 


\section{Sam and Abane}

maintenance and servicing schedules, passenger empowerment (a situation where passengers are empowered to caution, and upon refusal report, deviant drivers), driver training and retraining, periodic medical screening of drivers, mandatory rest stops for drivers on long journeys, driver award schemes, vehicle tracking and surcharging of at-fault drivers with the cost of repairs of damaged buses and property. For example, an operator revealed:

What we have decided to do is to implement a number of measures. One, to prevent driver fatigue we have identified mandatory rest stops on our operational routes, where the drivers are to stop in between trips, just to rest and stretch their limbs to reduce the tendency of driving tired. Two, we have developed vehicle tracking system on almost all our operational fleet to monitor driver behaviour in real-time. We also have a process where we retrain our drivers periodically; at least one training is organised for drivers nationwide. Furthermore, the company is trying to roll out award schemes to recognise and reward drivers who record no accident for a specified period (Traffic Operations Manager, Male, 51 years old).

Yet another operator remarked:

We have a police escort on all our enroute buses. If a police officer is with you, will you drive the way you like? Will you over-speed? Definitely, the presence of the police officer will be a check on the driver. Moreover, we have informed our drivers that they will be surcharged with the cost of repairs on buses they crash especially where investigations point to them as being at fault. This warning has made them very careful on the road (Transport Manager, Male, 54 years old).

On passenger security, the study noted that the major concerns were with highway robbery attacks, assault, baggage theft and insecurity at terminals. To address these, the officials revealed some countermeasures (capable guardi- ans): armed police escort on night buses, restricted mobile phone use by passengers while enroute, baggage identification system, installation of CCTV cameras at bus terminals, and a change in operational times for buses plying crime-prone areas. The comments below sum it all:

We have a police escort (for security reason the police escorts are not in uniform, but they are adequately armed). As a security measure against highway robbery, we advise and ensure that no passenger on board our buses makes or receives phone calls while enroute. For all you know some of these passengers act as informants for these armed robbers, giving them details of the movement of the buses. So to prevent that, we ensure that all phones are switched off during the journey. Only the driver and the police escort may make or receive calls during the journey. We also have baggage identification system in place to ensure baggage belonging to our passengers are secured. In this regard, passengers are given identification tags to use to identify their baggage. In case of accidental loss of a passenger's baggage, the passenger is asked to quantify the cost of the items in the bag and the company pays two-third of the total cost (Transport Manager, Male, 52 years old).

Another operator mentioned:

We have changed our operational times for some of our buses. We have also gotten the Ghana Police to help us with police personnel on some of our buses. We have also contracted a private security company to help keep the peace or some semblance of security at all our loading terminals and premises. Our operational staff have also been trained to be on the lookout for miscreants (Traffic Control Manager, Male, 39 years old).

Concerning securing baggage to wardoff potential robbery attacks on buses, an operator indicated: 
We don't allow baggage on board the buses. We lock them in the baggage compartment. This is to prevent baggage serving as motivation for armed robbery attacks since some of these armed robbers could also join the buses as passengers (Transport Manager, Male, 52 years old).

The aforementioned interventions align with Lynch and Atkins (1988) categorisation of safety and security interventions: patrol and security, design actions, media and information campaigns, and technology. The study observed that while patrol and security (i.e. police escort) was the dominant security countermeasure adopted; design actions (compulsory rest stops, periodic maintenance and servicing of vehicles), technology (vehicle tracking to monitor driver behaviour) and information (passenger empowerment, driver training and retraining) were the favoured safety countermeasures adopted by the surveyed operators.
Appraisal of adopted safety and security interventions

In appraising the aforementioned interventions, both passengers and operators' perspectives were sought. Firstly, the study examined visibility (or knowledge) of the interventions. The impression from Table 3 is that an appreciable number of surveyed passengers were quite aware of the safety $(57.1 \%)$ and security $(46.9 \%)$ interventions. However, visibility/ knowledge of the interventions was not enough to influence passengers' perceptions of safety and security on PT $(r=.12, n=167, p>.05)$.

Moreover, though important in their own rights, the study revealed that these interventions were appraised differently. Notably, countermeasures on driver over-speeding and recklessness $(43.2 \%)$ and a police escort $(41 \%)$ on night buses were highly commended by the participants (Table 3 ).

Table 3: Participants' appraisal of adopted interventions

\begin{tabular}{|c|c|c|c|}
\hline Interventions & & Frequency & Percent \\
\hline \multirow[t]{2}{*}{ Knowledge of safety interventions } & Yes & 156 & 57.1 \\
\hline & No & 117 & 42.9 \\
\hline \multirow{2}{*}{$\begin{array}{l}\text { Knowledge of security interven- } \\
\text { tions }\end{array}$} & Yes & 128 & 46.9 \\
\hline & No & 145 & 53.1 \\
\hline \multirow[t]{4}{*}{ Safety intervention appraisal } & Safer vehicles & 73 & 26.7 \\
\hline & Defensive driving training for drivers & 76 & 28.0 \\
\hline & $\begin{array}{l}\text { Countermeasures on driver over- } \\
\text { speeding and reckless driving }\end{array}$ & 118 & 43.2 \\
\hline & Frequent vehicle maintenance & 6 & 2.2 \\
\hline \multirow[t]{4}{*}{ Security intervention appraisal } & Police escort on night buses & 111 & 40.7 \\
\hline & $\begin{array}{l}\text { CCTV cameras on buses and termi- } \\
\text { nals }\end{array}$ & 59 & 21.6 \\
\hline & $\begin{array}{l}\text { Training on security consciousness } \\
\text { for drivers and passengers }\end{array}$ & 98 & 35.9 \\
\hline & A blend of the above interventions & 5 & 1.8 \\
\hline
\end{tabular}

Source: Field data, 2014 


\section{Sam and Abane}

On their effectiveness, the operators revealed that the interventions were yielding some desirable outcomes for their respective companies, in the form of a reduction in incidents (road traffic accidents, highway robbery attacks and baggage theft) involving their passengers and buses as enumerated below:

To run a company for over 5 years with 300 buses and record only 3 road traffic accidents means we are doing our best and that the measures are effective (Transport Manager, Male, 48 years old).

Yet another remarked:

Highway robbery attacks on our vehicles have reduced considerably because we are now known to be using police escorts during our journeys. These armed robbers are clever, once they see you be doing the right thing they stay clear of you. As a result, we have not encountered any highway robbery attack on our buses for the past 2 years or so (Transport Manager, Male, 51 years old).

Inferring from the propositions of the theories discussed earlier and the study findings, the paper affirms that as PT operators (management) institute appropriate safety and security interventions as well as orient and train their staff (drivers inclusive) on safety and security policies and procedures, the PT system will function effectively resulting in enhanced passenger safety and security in the country.

\section{CONCLUSION}

Given the high safety and security risk associated with PT, ensuring passenger safety and security should be prioritised. What makes this imperative is the fact that PT conveys a larger number of passengers over time and space. Moreso, as the study found, passengers' personal safety and security encounters on PT informs their safety and security evaluations of the service, even though the media also play a significant role in this regard.
Inferring from the relative gains the surveyed operators reported by way of these interventions, it could be concluded that the operators' recent interventions have been effective and thus need to be sustained. Further, it can also be argued that PT passenger safety and security situation in the country is improving. However, to sustain this, this paper calls for effective collaboration between the stakeholders (relevant government agencies and PT operators). As reckoned by Forsblom (2002), "any measure taken in this regard requires extensive cooperation between the various actors. Action by individual players may not be sufficient to address the issue" (p. 4).

\section{IMPLICATIONS FOR PRACTICE AND POLICY}

Undoubtedly, the majority of city dwellers use a form of PT every day. Improving PT would thus address the needs of the majority. The study advocates for a regular review of the regulatory framework establishing public transportation by Metropolitan, Municipal and District Assemblies (MMDAs). It is important to note that regulations that were appropriate at the time that they were proposed have often been rendered obsolete by changes in circumstances, thus inhibiting the regulation of public transport services in line with changing requirements. Hence, periodic monitoring and regulation of the safety and security interventions of transport operators in the country are recommended. In this way, Ghana could tap fully into their benefits while still managing their shortcomings for the good of the nation.

Finally, the study revealed that considerable passenger safety and security gains have been made by the operators as a result of the enumerated interventions. However, the magnitude of the gains (quantitatively), as well as their impact on the overall passenger safety and security situation in Ghana was not established in this study as it is the focus of a follow-up study. This, however, does not negate the findings of this study as it reflects the perspectives of both the surveyed operators and passengers. 
COMPLIANCE WITH ETHICAL STANDARDS

We declare no conflict of interest. Also, informed consent was obtained from all participants included in the study. Moreover, we received no financial support to conduct or publish the study.

\section{REFERENCES}

Abane, A. M. (1993b). Mode choice for the journey to work among formal sector employees in Accra, Ghana. Journal of Transport Geography, 1(4): 119-129.

Abane, A. M. (2011). Travel behaviour in Ghana: Empirical observations from four metropolitan areas. Journal of Transport Geography, 19(1): 313-322.

Benjamin, J., Hartgen, D. T., Owens, T. W. and Hardiman, M. (1994). Perception and incidence of crime on public transit in small systems in the Southeast. Transportation Research Record,1433: 195-200.

Branic, N. (2015). "Routine activities theory". In W. G. Jennings (Ed.). Encyclopedia of Crime and Punishment. Malden, MA: WileyBlackwell

Clarke, R. and Eck, J. (2005). Crime analysis for problem solvers in 60 small steps. Washington, DC: Office of Community Oriented Policing Services, United States Department of Justice.

Cohen, L. and Felson, M. (1979). Social change and crime rate trends: A routine activities approach. American Sociological Review, 44: 588-608.

Creswell, J. W. (2014). Qualitative, quantitative and mixed methods approaches, 4th Edition. Los Angeles, USA: Sage Publications, Inc.

Forsblom, M. (2002). Security brings satisfaction and customers. Retrieved from http:// best2005.net/content/download/905/4166/ file/Security\%20brings\%20satisfaction\% 20 and $\% 20$ customers.pdf.

Iles, R. (2005). Public transport in developing countries. UK: Elsevier Ltd.

Ingalls, G. L., Hartgen, D. T. and Owens, T. W. (1994). Public fear of crime and its role in bus transit use. Transportation Research Record, 1433: 201-211.

Joewono, T. B. and Kubota, H. (2006). Safety and security improvement in public transportation based on public perception in developing countries. IATSS Research, 30(1): 86100 .

Lynch, G. and Atkins, S. (1988). The influence of personal security fears on women's travel patterns. Transportation, 15: 257-277.

Mackett, R. and Babalik, E. (2003). New urban rail systems: a policy-based technique to make them more successful. Journal of Transport Geography, 11: 151-164.

National Road Safety Commission (NRSC). (2010). National road accident report. Accra: NRSC.

Needle, J. and Cobb, R. (1997). Improving Transit Security: Synthesis of Transit Practice 21. Washington, DC: National Academy Press.

Newton, A. D. (2014). "Crime on public transport. In Encyclopedia of Criminology and Criminal Justice, 709-720. London: Springer

Petersen, D. (1975). Safety management: A human approach. Englewood, New Jersey: Aloray

Poku-Boansi, M. and Adarkwa, K. K. (2013). The determinants of demand for public transport services in Kumasi, Ghana. Journal of Science and Technology, 33(3): 60-72 


\section{Sam and Abane}

Potoglou, D., Robinson, N., Kim, C. M., Burge, P. and Warnes, R. (2010). Quantifying individuals' trade-offs between privacy, liberty and security: The case of rail travel in UK. Transportation Research A: Policy and Practice, 44(3): 169-181. doi:10.1016/ j.tra.2009.12.006

Reed, T. B., Wallace, R. R. and Rodriguez, D. A. (2000). Transit passenger perceptions of transit-related crime reduction measures. Transportation Research Record, 1731: 130141.

Sam, E. F., Adu-Boahen, K. and KissahKorsah, K. (2014). Assessing the factors that influence public transport mode preference and patronage: Perspectives of students of University of Cape Coast (UCC), Ghana. International Journal of Development and Sustainability, 3(2): 323-336.

Shen, L. D., Ospina, D., Zhao, F. and Elbadrawi, H. (1997). The analysis of technologies and methodologies adopted by U.S. Transit Agencies to enhance transit security. National Urban Transit Institute, University of South Florida, Tampa.

Smith, M. and Cornish, B. (2006). Secure and tranquil travel: Preventing crime and disorder on public transport. London: UCL Jill Dando Institute of Crime Science.

Stafford, J. (2003). "Safer Travel by Design: Reducing Crime on Transport." Proceedings of the Institution of Civil Engineers Municipal Engineer, 156(2): 87-88. doi:10.1680/ muen.2003.156.2.87.

Wallace, R. R., Rodriguez, D. A., White, C. and Levine, J. (1999). Who noticed, who cares?: Passenger reactions to transit safety measures. Transportation Research Record, 1666: 133-138.

World Bank (n.d). Cities on the move: A World Bank urban transport strategy review. Re$\mathrm{t} \mathrm{r}$ i e $\mathrm{v}$ e d f $\mathrm{r}$ o $\mathrm{m}$ h t $\mathrm{t} \mathrm{p}: / /$ siteresources.worldbank.org/ INTURBANTRANSPORT/Resources/ chapter5.pdf

World Health Organisation (WHO), (2013). Global status report on road safety: Supporting a decade of action. Retrieved on December 12, 2015 from http://www.un.org/en/ roadsafety/pdf/roadsafety2013_eng.pdf. 